\title{
Ribosomal RNA gene expression and chromosome aberrations in bovine oocytes and preimplantation embryos*
}

\author{
Poul Hyttel ${ }^{1}$, Dorthe Viuff ${ }^{2}$, Trudee Fair ${ }^{3}$, Jozef Laurincik ${ }^{4}$, \\ Preben D. Thomsen ${ }^{1}$, Henrik Callesen ${ }^{5}$, Peter L. A. M. Vos ${ }^{6}$, \\ Peter J. M. Hendriksen ${ }^{6}$, Steph J. Dieleman ${ }^{6}$, Karl Schellander ${ }^{7}$, \\ Urban Besenfelder ${ }^{8}$ and Torben Greve ${ }^{2}$ \\ ${ }^{1}$ Department of Anatomy and Physiology and ${ }^{2}$ Department for Clinical Studies, Reproduction, \\ Royal Veterinary and Agricultural University, Groennegaardsvej 7, 1870 Frederiksberg C, \\ Denmark; ${ }^{3}$ Department of Animal Science and Production, Lyons Research Farm, University \\ College Dublin, Ireland; ${ }^{4}$ Konstantin the Philosopher University and Research Institute of \\ Animal Production, Nitra, Slovak Republic; ${ }^{5}$ Department of Animal Breeding and Genetics, \\ Danish Institute of Agricultural Sciences, 8830 Tjele, Denmark; ${ }^{6}$ Department of Farm Animal \\ Health, Faculty of Veterinary Medicine, Yalelaan 7, 3584 CL Utrecht, The Netherlands; \\ ${ }^{7}$ University of Bonn, Faculty of Agriculture, Institute of Animal Breeding Science, Endenicher \\ Allee 15, 53115 Bonn, Germany; and ${ }^{8}$ IFA-TULLN, Department of Biotechnology in Animal \\ Production, Konrad Lorenz Str. 20, 3430 TULLN, Austria
}

\begin{abstract}
This review focuses on the key features of development of the bovine oocyte and embryo, with comparisons of the developmental characteristics of embryos produced in vivo and in vitro. The oocyte is transcriptionally quiescent in the primordial and primary follicle. In the secondary follicle transcription is initiated in the oocyte and a ribosome-synthesizing nucleolus is established in this cell. Transcription and nucleolar activity are enhanced in the tertiary follicle during oocyte growth. When the oocyte reaches approximately $110 \mu \mathrm{m}$ in diameter, corresponding to a follicle of about $3 \mathrm{~mm}$ in diameter, transcription ceases and the nucleolus is inactivated, forming a dense spherical remnant. During the final phase of follicular dominance this remnant becomes vacuolated and, in conjunction with resumption of meiosis, it disperses. The rRNA genes are apparently re-activated during the four-cell stage, that is, the third cell cycle after fertilization, but a nucleolus is not formed. During the subsequent cell cycle, that is, during the eight-cell stage, ribosome-synthesizing nucleoli are again established. Bovine embryos produced in vitro apparently display the same pattern of nucleolus development as that in embryos developed in vivo. Examination of the ploidy of embryonic cells using fluorescence in situ hybridization has revealed that the production of bovine embryos in vitro is associated with increased chromosome aberrations in the embryos. Blastocysts produced in vitro display a significantly higher rate of mixoploidy, that is, when the embryo consists of both normal diploid and abnormal polyploid cells, than that in embryos developed in vivo. The rate of mixoploidy among embryos produced in vitro increases with increasing developmental stage. Moreover, after fertilization in vitro, initially there is a high rate of 'true' polyploidy, that is, when all cells of the embryos are polyploid. However, the polyploid embryos are eliminated before they cleave beyond the eight-cell stage, the stage at which major activation of the embryonic genome occurs in cattle.
\end{abstract}

During the past decade, production of bovine embryos in vitro has become a routine research tool in many laboratories, and it is now being implemented in applied

Email: poh@kvl.dk

*This article is based on a presentation given at the British Society of Animal Science symposium 'Early Regulation of Mammalian Development' held in Aberdeen in September 2000. breeding programmes in several countries. Moreover, towards the end of the last decade, the production of transgenic offspring in the large domestic species by cloning based on nuclear transfer from cultured embryonic, fetal or even adult somatic cells became a reality (for a review, see Wilmut et al., 2000). The rapid expansion of these biotechnologies has not been without problems, leading to an increased focus on embryo quality and viability. Thus, 
although thousands of calves have been born from embryos produced in vitro, problems with abortions, increased birth weights, dystocia and high rates of neonatal mortality have been widely reported (for a review, see Farin and Farin, 1995; Walker et al., 1996; Kruip and den Daas, 1997). In the case of nuclear transfer, the situation is even more pronounced: only $1-2 \%$ of the reconstructed embryos become live offspring (for a review, see Wilmut et al., 2000). With these substantial problems in mind, more emphasis has been devoted to understanding of the cell biological processes that regulate initial embryonic development and on which technological manipulation of the embryo may have detrimental impacts. Two such basic cell biological factors of crucial importance for the developmental potential of the embryo are an adequate protein synthetic machinery and a normal ploidy of the chromosomal compartment.

\section{Ribosomal RNA gene expression and nucleolus biology}

The bovine oocyte, zygote and embryo have a profound need for protein synthesis. However, the mRNA transcripts for these proteins are not synthesized throughout development, but rather during specific phases thereof. These phases of transcription correspond to developmental phases in which protein synthesis in particular is needed, such as during the oocyte growth phase, or to phases in which protein synthesis has to be redirected to fulfil new tasks, as after the major activation of the embryonic genome during the fourth cell cycle after fertilization, that is the eight-cell stage, when initial cell differentiation is prepared.

An adequate cytoplasmic pool of ribosomes is a prerequisite for protein synthesis. The ribosomes are synthesized by transcription of the ribosomal RNA (rRNA) genes, processing of the transcripts and addition of numerous ribosomal proteins to them. The rRNA genes are located in multiple repeats in the so-called nucleolus organizer regions (NORs) of the chromosomes. The diploid bovine genome comprises ten NORs localized to the telomere regions of chromosomes 2, 3, 4, 11 and 28 (Di Berardino et al., 1990). Active transcription of the rRNA genes results in the formation of a nucleolus that develops around the NORs (for a review, see Wachtler and Stahl, 1993). The number of nucleoli varies from one type of cell to another and several NORs may contribute to the formation of a single nucleolus. The nucleolus is the most prominent nuclear organelle and the site of formation of the ribosomal subunits. The subunits subsequently leave the nucleus through the pores of the nuclear envelope and associate to form ribosomes in conjunction with translation of mRNAs. The nucleolus contains three main ultrastructural components: the two fibrillar components, consisting of the fibrillar centres and the dense fibrillar component, and the granular component. These components of the so-called fibrillo-granular nucleolus reflect the steps in the biosynthesis of ribosomes according to the following model: (i) the fibrillar centres house the enzymatic apparatus for transcription, including
RNA polymerase I which is directly responsible for this process; (ii) the dense fibrillar component carries the nascent unprocessed transcripts; and (iii) the granular component represents processed transcripts associated with proteins in the form of pre-ribosomal particles. According to this model, the transcription of the rRNA genes is believed to occur at the interface between the fibrillar centres and the dense fibrillar component (Hozak et al., 1994).

The bovine oocyte and embryo present fibrillo-granular nucleoli during the periods when protein synthesis is particularly important, that is, during the oocyte growth phase and after the major activation of the embryonic genome during the fourth cell cycle after fertilization. During the more quiescent phases, certain nucleolar components are absent, indicating a lack of ribosome synthesis. In the following sections, rRNA gene expression, as visualized by nucleolar function in the bovine oocyte and preimplantation embryo, is addressed.

\section{Transcription and nucleolus biology during oocyte growth, capacitation and maturation}

As the follicle develops from the primordial to the tertiary (antral) stage, the oocyte undergoes a parallel growth phase during which it gradually achieves its characteristic architecture (Fair et al., 1997a). During this phase of development, the oocyte shows a high rate of transcription and translation resulting in the formation of RNAs and proteins both for immediate use in oocyte growth and for storage. With the accumulation of this stored 'information', the oocyte gradually acquires its developmental competence, as addressed later. In a study to characterize the cell biology of the initial phases of oocyte growth, small explants of ovarian cortex were incubated with $\left[{ }^{3} \mathrm{H}\right]$ uridine and processed for autoradiography and transmission electron microscopy (Fair et al., 1997b; Fig. 1).

In bovine primordial follicles, the oocytes are transcriptionally quiescent, as demonstrated by a lack of autoradiographic labelling. In accordance with this finding, the oocyte nucleolus lacks the fibrillar portion and is exclusively composed of a granular component signalling the lack of ribosome-synthesizing activity. In contrast, murine oocytes present a fibrillo-granular nucleolus during the primordial and primary stages of development (Chouinard, 1971). The bovine oocyte presents fibrillogranular nucleoli during the earlier stages of the first meiotic prophase that occur during embryonic development, namely leptotene, zygotene and pachytene stages (Fair et al., 1998). It may be speculated that the comparatively longer duration of oocyte development in cattle as compared with that in mice requires a more profound degree of oocyte quiescence in the resting primordial follicle.

In primary follicles, the oocytes remain transcriptionally quiescent, as evaluated by the $30 \mathrm{~min}\left[{ }^{3} \mathrm{H}\right]$ uridine incubation, and the nucleoli exclusively present a granular component. However, on some occasions a presumptive 


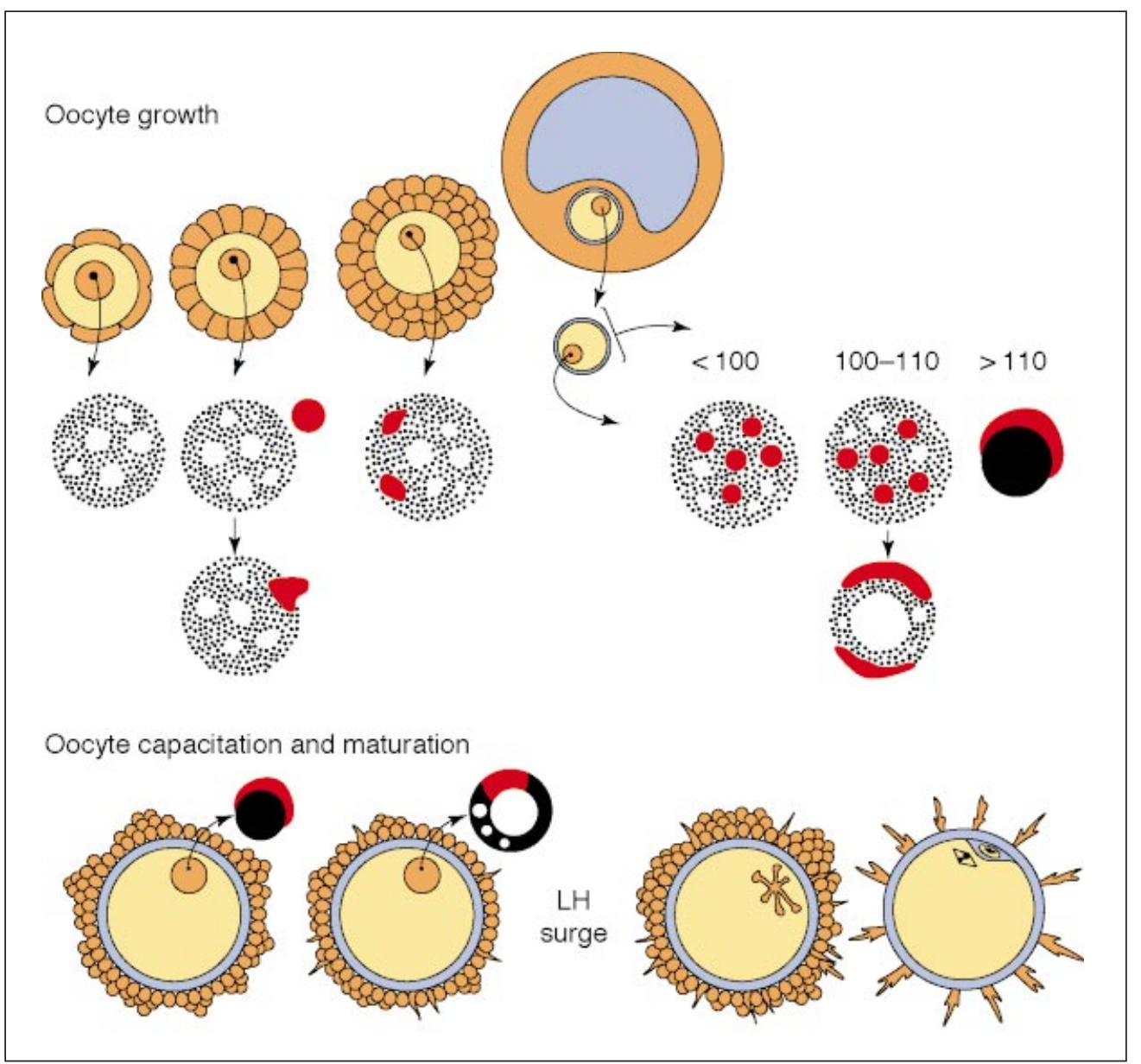

Fig. 1. The ultrastructure of the oocyte nucleoli during growth, capacitation and maturation of the bovine oocyte. Fibrillar centres invade the granular nucleoli in the secondary follicle and are marginalized towards the end of oocyte growth with the formation of the dense nucleolar remnant as the result. The remnant is vacuolized towards the end of oocyte capacitation and is dispersed in conjunction with resumption of meiosis. There are no signs of nucleoli during or after germinal vesicle breakdown.

fibrillar centre is observed adjacent to, or extending into, the superficial zone of the granular nucleoli. It is believed that these presumptive fibrillar centres are associated with the rRNA genes. Thus, the fusion of the granular nucleolus with the presumptive fibrillar centres is thought to signal the first step towards the assembly of a functional nucleolus capable of rRNA transcription and processing, that is, ribosome formation.

In secondary follicles, transcription is initiated in the oocytes, as signalled by a weak autoradiographic labelling over the nucleoplasm and the nucleoli. In the nucleoli, the fibrillar centres become completely embedded in the superficial zone of the granular component forming fibrillogranular nucleoli. As signalled by the autoradiographic labelling of the nucleoli, rRNA gene transcription is activated to a detectable level. Thus, in the secondary follicle, the oocyte genome is activated to a certain degree allowing for synthesis of both mRNA and rRNA.

In early tertiary follicles, the diameter of the oocyte increases further. During this phase of development the oocyte displays a high rate of transcription, as signalled by autoradiographic labelling over the nucleoplasm and the nucleoli. Accordingly, the oocyte nucleoli are fibrillogranular and present many distinct fibrillar centres deeply embedded in the granular component.

Transcriptional activity and nucleolar function of oocytes in relation to their diameters were characterized in tertiary follicles exceeding about $1 \mathrm{~mm}$ in diameter. In this study, oocytes were harvested from ovaries by slicing, that is, repeated cutting with a series of razor blades mounted at a distance of approximately $1 \mathrm{~mm}$. The inside diameter of the zona pellucida of the oocytes was measured using an ocular equipped with a measurement scale. Subsequently, the oocytes were incubated for $30 \mathrm{~min}$ in $\left[{ }^{3} \mathrm{H}\right]$ uridine and processed for autoradiography and transmission electron microscopy (Fair et al., 1996; Fig. 1). Other oocytes were processed for immunocytochemical localization of RNA polymerase I and studied by confocal laser scanning 
microscopy (Fair et al., in press). Oocytes of 80-100 $\mu \mathrm{m}$ in diameter display active transcription, as signalled by pronounced autoradiographic labelling over the nucleoplasm as well as the nucleoli. Accordingly, the nucleoli are fibillo-granular and present numerous fibrillar centres distributed in the granular component. RNA polymerase I is localized to the fibrillar centres in all oocytes. In oocytes of $100-110 \mu \mathrm{m}$ in diameter, the rate of transcription decreases, as signalled by less prominent autoradiographic labelling of the nucleoplasm and a lack of nucleolar labelling. Accordingly, the fibrillar centres of the nucleoli are peripherally dislocated to a couple of lentiform structures on the surface of the granular component, which develops a large central vacuole. The marginalization of the fibrillar centres presumably signals the retraction of the rRNA genes from the nucleolus and thereby the inactivation of this organelle. RNA polymerase I can still be localized to the fibrillar centres in all oocytes. In oocytes of 110-120 $\mu \mathrm{m}$ in diameter, transcription essentially ceases, as signalled by the lack of autoradiographic labelling. Accordingly, the nucleoli extrude all granules and gradually compact into inactive electron-dense fibrillar spheres with a fibrillar centre attached as a halo. In some oocytes, the fibrillar spheres still display a central vacuole. At this stage of development, the term nucleolar remnant is more appropriate as the ribosome synthesis has definitely ceased. Nevertheless, RNA polymerase I can still be localized to the fibrillar centres in most oocytes. The described pattern of nucleolar inactivation is in accordance with previous observations in cattle (Crozet et al., 1986). Oocytes $>120 \mu \mathrm{m}$ in diameter display similar features to those of $110-120 \mu \mathrm{m}$ in diameter with respect to morphology and lack of autoradiographic labelling, except that vacuolated nucleolar remnants are not observed. However, in many oocytes in this size category, fragmentation of the nucleolar remnants to several smaller electron-dense fibrillar spheres is noted. RNA polymerase I can be localized only in about one-third of the oocytes at this stage of development.

Although oocyte transcription effectively ceases when the follicle reaches $3 \mathrm{~mm}$ in diameter, the oocyte does not enter quiescence. During the succeeding follicular dominance it continues development through a process that may be referred to as oocyte capacitation (Assey et al., 1994; Hyttel et al., 1997). In particular, during the last period of follicular dominance in the ovulatory follicle after luteolysis, but before the LH surge, marked changes are noted in the oocyte nucleus, namely the germinal vesicle (Fig. 1): the nuclear envelope becomes undulating and the nucleolar remnant displays a vacuole of increasing size. As dispersal of the nucleolar remnant precedes germinal vesicle breakdown, the oocyte prepares for resumption of meiosis even before stimulation by the $\mathrm{LH}$ surge.

During the $24 \mathrm{~h}$ period from the $\mathrm{LH}$ surge to ovulation, the oocyte undergoes its final maturation, including progression of meiosis to metaphase II and a series of cytoplasmic modifications (Kruip et al., 1983; Hyttel et al., 1986). Resumption of meiosis requires a short burst of transcription in the cumulus-oocyte complex. Thus, it has been demonstrated that, at least during conjunction with oocyte maturation in vitro, the complex displays transcription over the initial $1-2 \mathrm{~h}$ of maturation when transcripts necessary for driving germinal vesicle breakdown, as well as metaphase I transition, are synthesized (Sirard et al., 1989; Kastrop et al., 1991). Results based on $\left.{ }^{35} \mathrm{~S}\right]$ UTP incorporation indicate that at least part of this transcription occurs in the oocyte (Memili et al., 1998). As discussed earlier, the nucleolar remnant is dissolved before germinal vesicle breakdown, and throughout meiosis up to metaphase II there are no morphological signs of nucleoli. Moreover, it has not been possible to localize RNA polymerase I by immunocytochemistry during this phase of development (Fair et al., in press). This finding is in contrast to the situation during mitosis, in which this enzyme remains associated with the NORs of the chromosomes. Thus, meiosis appears to have a more profound effect on the disassembly of the nucleolus than on mitosis.

Briefly, transcription and nucleolar ribosome synthesis are initiated in bovine oocytes in the secondary follicle, and towards the end of the oocyte growth phase, when the oocyte is about $110 \mu \mathrm{m}$ in diameter, these biological processes cease. The resumption of meiosis is associated with a profound disassembly of the nucleolus.

\section{Achievement of oocyte competence during oocyte growth, capacitation and maturation}

The competence of the oocyte for completing final meiotic maturation in vitro is strongly correlated with oocyte diameter and thus with the cell biological development of the oocyte described earlier. Growing and fully grown bovine oocytes collected by slicing of ovaries were grouped according to inside diameter of the zona pellucida and matured in vitro to test for competence for completing meiotic maturation to metaphase II (Fair et al., 1995). Among oocytes $<100 \mu \mathrm{m}$ in diameter, $23 \%$ were at the germinal vesicle stage after $24 \mathrm{~h}$ of in vitro maturation, which was a significantly higher proportion than that among oocytes of 100-109 (8\%), 110-119 (5\%) and $>120 \mu \mathrm{m}(2 \%)$. Among oocytes < 100 and 100-109 $\mu \mathrm{m}$ in diameter, 22 and $23 \%$, respectively, of those that resumed meiosis blocked at metaphase I, which was significantly more than in any of the two larger groups (10 and $12 \%$ ). Among oocytes of $110-119 \mu \mathrm{m}$ and $>120 \mu \mathrm{m}$ equally high proportions (76 and $81 \%$, respectively) reached metaphase II. Thus, at a diameter of about $100 \mu \mathrm{m}$, oocytes acquire the full competence for resumption of meiosis, and at a diameter of about $110 \mu \mathrm{m}$, they acquire the full competence for completing meiotic maturation to metaphase II. It has been demonstrated that oocyte competence increases with increasing follicular diameter in cattle (Fuhrer et al., 1989; Lonergan et al., 1994), pigs (Motlik et al., 1984; Motlik and Fulka, 1986) and goats (de Schmedt et al., 1994). In all these species, full meiotic competence appears to be acquired in follicles of about $3 \mathrm{~mm}$ which, at least in cattle, corresponds to an oocyte of about $110 \mu \mathrm{m}$ in 
diameter (Fair et al., 1995). The present data also concur with the observation that meiotic competence is acquired progressively (Thibault et al., 1987).

However, with respect to competence to sustain embryonic development to the blastocyst stage under production conditions in vitro, recent studies have demonstrated that the oocyte only reaches a basic level of competence at a follicular diameter of $3 \mathrm{~mm}$. Oocytes were harvested by ovariectomy of heifers that were stimulated with equine chorionic gonadotrophin (eCG), but in which the endogenous LH surge was suppressed by Norgestomet implants, to test the competence for blastocyst development in vitro of oocytes from dominant follicles (Hendriksen et al., 2000). Oocytes that were collected at $60 \mathrm{~h}$ after the onset of eCG treatment from follicles $>8 \mathrm{~mm}$ and were matured, fertilized and cultured in vitro resulted in $41 \%$ blastocysts, which was a significantly higher proportion than that achieved from oocytes collected from follicles of $5-8 \mathrm{~mm}$ in diameter (25\%). Moreover, oocytes that were collected at $104 \mathrm{~h}$ after the onset of eCG treatment resulted in a blastocyst formation rate of $66 \%$, which was significantly higher than the proportion (26\%) obtained from oocytes originating from $2-8 \mathrm{~mm}$ follicles in ovaries collected from an abattoir. Thus, the developmental competence of the oocyte is increased during follicular dominance through the process of oocyte capacitation, as referred to earlier in this review.

Together, these experiments demonstrate that the oocyte achieves a basic level of competence for maturation and embryonic development at a diameter of about $110 \mu \mathrm{m}$, corresponding to a follicular diameter of about $3 \mathrm{~mm}$, and that this competence is enhanced through oocyte capacitation during follicular dominance.

\section{Transcription and nucleolus biology during fertilization and initial embryonic development}

As discussed earlier, the initial development of the preimplantation embryo is governed by gene transcripts and polypeptides produced by and stored in the oocyte during its development (Schultz, 1993). However, after one to three cleavage divisions, control of development is taken over by the expression of portions of the embryonic genome, and the maternally derived transcripts and proteins are gradually degraded (Telford et al., 1990; Watson et al., 1996, 1999; De Sousa et al., 1998). The transition from maternal to embryonic control of development is a gradual process. In mice and rabbits, it has been demonstrated that a minor transcriptional activation occurring at the G2 stage of the first cell cycle after fertilization precedes a major activation at the G2 stage of the second cell cycle in mice and at the fourth to fifth cell cycle in rabbits (for a review, see Thompson, 1996). Accordingly, long-term incubation with $\left[{ }^{3} \mathrm{H}\right]$ uridine has revealed transcription during the first (Hay-Schmidt et al., in press) and second cell cycle (Plante et al., 1994; Hyttel et al., 1996; Viuff et al., 1996) in cattle, well before the major transcriptional activation that takes place during the fourth cell cycle (Camous et al., 1986). In pigs, the major transcriptional activation is observed during the fourth cell cycle (Tomanek et al., 1989), but whether this activation is preceded by an earlier minor activation has not been investigated.

The developing preimplantation embryo has a profound need for synthesis of proteins both for housekeeping and cell differentiation. Therefore, it is not unexpected that the rRNA genes are among the genes activated in the major cascade, and, moreover, it is clear that a proper activation of these genes is crucial for continued embryonic development (King et al., 1988; Kopecny et al., 1989; Tomanek et al., 1989). Accordingly, it has been demonstrated that bovine zygotes and embryos show a quantitative decrease in protein synthesis from fertilization up to the eight-cell stage, that is, the time of the major transcriptional activation, upon which synthesis increases again up to the blastocyst stage (Frei et al., 1989). The decrease may be caused by decreasing contents of mRNA or ribosomes in the embryo, or a combination of the two.

The activation of the rRNA genes of the embryonic genome can be visualized ultrastructurally through the formation of nucleoli in the blastomeres of the embryo. However, the application of different cell biological techniques in embryo technology during the past few years has allowed for molecular understanding of this process, by the use of immunocytochemistry for the localization of specific proteins of importance for nucleolar function, and fluorescence in situ hybridization (FISH) for the localization of the rRNA genes and transcripts. These techniques have been applied to bovine embryos produced in vitro and comparisons have been made with embryos developed in vivo (Viuff et al., 1998; Laurincik et al., 2000).

As described earlier, at the end of the oocyte growth phase the oocyte nucleoli are inactivated and, in conjunction with resumption of meiosis, disassembled (Fair et al., 1996). Re-assembly of the nucleoli in the bovine embryo occurs as a protracted process over the initial four to five cell cycles (Camous et al., 1986; King et al., 1988; Kopecny et al., 1989; Laurincik et al., 2000; Fig. 2). After enclosure of the maternal and paternal chromatin by the nuclear envelope and swelling of the pronuclei, spheres of tightly packed fibrillar material emerge in each of the pronuclei. Since during the fourth cell cycle these entities serve as the physical site in which nucleoli develop, they are often referred to as nucleolus precursor bodies. The precursor bodies develop vacuoles with the progression of the cell cycle. These bodies share morphological similarities with the tightly packed core of the nucleolar remnants in the fully grown oocyte. Accordingly, RNA polymerase I can be localized by confocal laser scanning microscopy to the presumptive nucleolar precursor bodies, as is often also the case with the nucleolar remnants (Fair et al., 2001). Thus, the nucleolar remnants are dispersed at the resumption of meiosis before germinal vesicle breakdown, but at least some of the components are re-assembled to form the nucleolus precursor bodies in the pronuclei after 


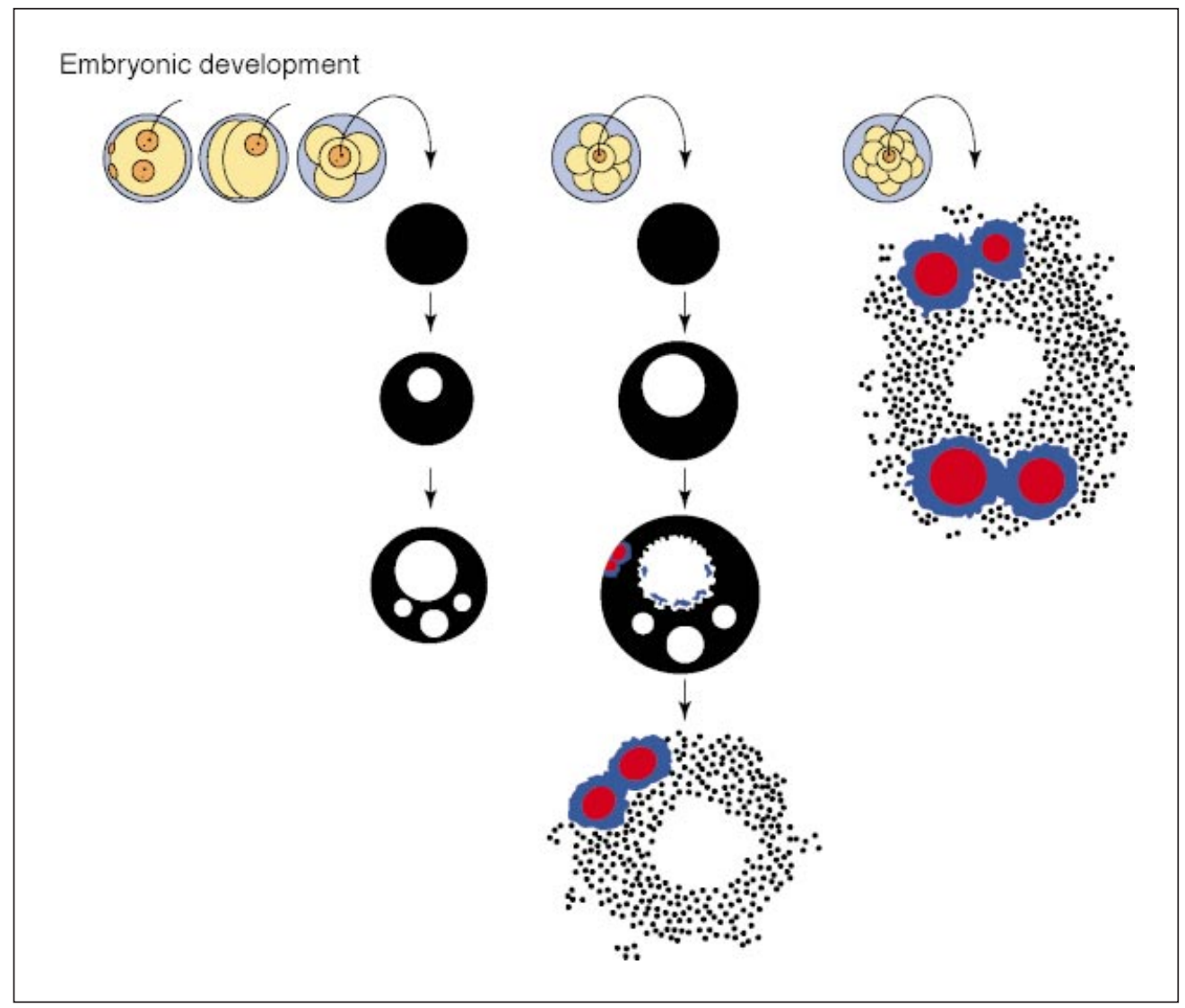

Fig. 2. The ultrastructure of the nucleoli during initial development of the bovine embryo. During the initial three cell cycles, nucleolus precursor bodies undergo vacuolization. During the fourth cycle, fibrillo-granular nucleoli develop through formation of a dense fibrillar component (blue) and fibrillar centres (red) in the periphery of the precursor bodies followed by formation of a granular component. During the fifth cell cycle, fibrillo-granular nucleoli are formed at the onset of the cell cycle.

meiosis. The nucleolus precursor bodies disassemble in conjunction with the first mitosis, that is, at synkaryosis.

In two- and four-cell embryos, that is, during the second and third cell cycles after fertilization, nucleolus precursor bodies assemble in the blastomere nuclei after mitosis and, with progression of the cell cycle, they display vacuolization. However, fibrillo-granular nucleoli are never observed. For unknown reasons, RNA polymerase I cannot be localized to the precursor bodies during the second and third cell cycles.

Early in the eight-cell stage, that is, at the onset of the fourth cell cycle, nucleolus precursor bodies emerge again after mitosis. With the progression of this cell cycle, these entities first develop an eccentrical primary vacuole and later several peripheral secondary vacuoles. Towards the end of the cell cycle, a dense fibrillar nucleolar component surrounding tiny fibrillar centres develops in the peripheral zone of the precursor bodies. The centres are closely associated with heterochromatin. It is assumed that this chromatin arrangement allows for the rRNA genes to be localized in the centres as a prerequisite for rRNA gene transcription. In addition, portions of dense fibrillar component form at the inner lining of the large primary vacuoles (Kopecny et al., 1989; Laurincik et al., 2000). Subsequently, the dense fibrillar component and the fibrillar centres develop and a presumptive granular component consisting of pre-ribosomal particles emerges and occupies the remaining portion of the precursor body. Thus, through this process, fibrillo-granular nucleoli emerge. Concomitant with the first observation of fibrillar centres by transmission electron microscopy towards the end of the fourth cell cycle, for the first time since the zygote stage, it is possible to localize RNA polymerase I to the fibrillar centres by confocal laser scanning microscopy. During the fifth cell cycle, fibrillo-granular nucleoli are already formed at the onset of the cycle, indicating that the meiotically induced inactivation of the rRNA genes has ceased.

In addition to the ultrastructural and immunocytochemical approaches, a pig 18S/5.8S/28S DNA probe has been used for the localization of rRNA genes and transcribed rRNA by FISH, combined with localization of nucleolar proteins by silver staining, on spreads of fixed interphase nuclei and sporadic mitotic configurations from bovine embryos produced in vitro (Viuff et al., 1998). The 
slides were processed for FISH either after RNase treatment (hybridization exclusively to the rRNA genes) or without RNase treatment (hybridization to both rRNA genes and their transcripts). Both RNase- and non-RNase-treated twocell embryos as well as RNase-treated four-cell embryos present up to ten small spots of labelling that co-localize with nucleolar proteins. This labelling pattern corresponds to the ten NORs found in the bovine genome. In contrast, the non-RNase treated four-cell embryos present larger labelled clusters that typically consist of one or more large foci localized in the periphery of a prominent cluster of small spots. These clusters co-localize with larger masses of nucleolar proteins. This marked difference is thought to indicate rRNA transcription as early as the third cell cycle before the formation of fibrillo-granular nucleoli, although the re-localization of maternal rRNA, as demonstrated in Xenopus embryos, cannot be excluded (Verheggen et al., 1998). The occurrence of rRNA transcription before the fourth cell cycle in bovine embryos is in agreement with the study of Bilodeau-Goeseels and Schultz (1997), in which northern blot analyses revealed a small increase in the rRNA hybridization signal in a combination of two- and four-cell embryos compared with that in zygotes. The significance as well as the fate of the rRNA transcribed during the third cell cycle has remained an enigma so far. Another interesting feature is that the silver staining nucleolar proteins, which are associated with the NORs of the interphase chromosomes during the second and third cell cycles, are not detectable on metaphase chromosomes until the mitosis completing the fourth cell cycle, that is, the mitosis from the eight-cell to the 16-cell stage (King et al., 1988). Thus, during the interphases of the first three cell cycles after fertilization, the NORs appear to have higher affinity for the nucleolar proteins than during metaphase. These findings support the notion that the embryos do not recover from the impact of meiosis until after the fourth cell cycle.

Bovine embryos produced in vitro by oocyte maturation, fertilization and subsequent embryo co-culture with bovine oviduct epithelial cells and those developed in vivo in the oviducts and uteri display a comparable degree of nucleolus development and, thus, presumably rRNA gene activation (P. Hyttel, J. Laurincik and B. Avery, unpublished).

\section{Chromosome aberrations in bovine preimplantation embryos}

It has been demonstrated by classic cytogenetic methods that bovine embryos produced in vitro present chromosome aberrations; however, the estimates of the frequency of such conditions have been variable. For example, abnormalities have been reported in $13.7 \%$ of two- to four-cell embryos (Iwasaki et al., 1989), in $80 \%$ of five- to ten-cell embryos (Yoshizawa et al., 1999) and in 38\% of blastocysts (Iwasaki and Nakahara, 1990), as well as in $36.3 \%$ and $39.2 \%$ of embryos at days 2 and 5 after in vitro insemination, respectively (Kawarsky et al., 1996). These differences may,

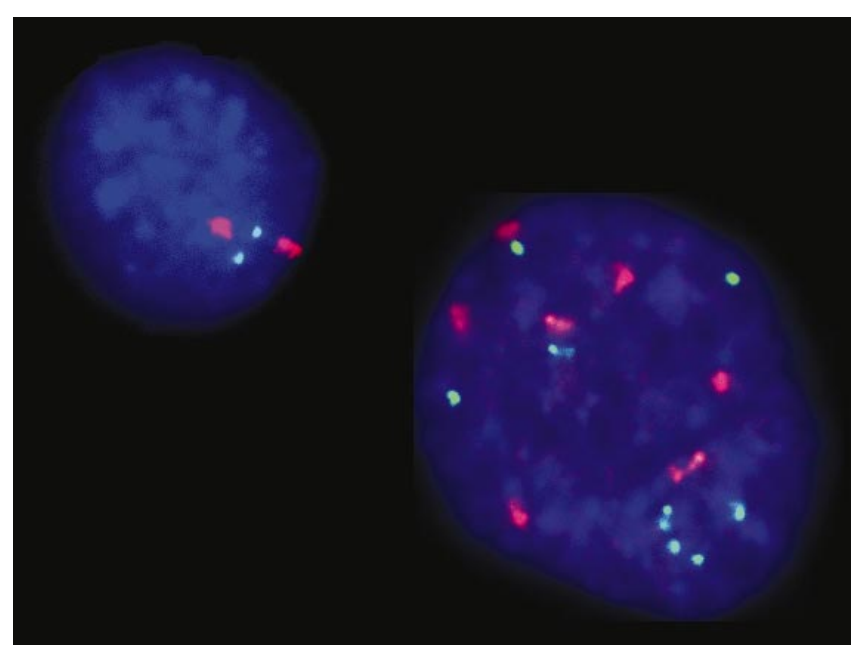

Fig. 3. Two bovine blastocyst nuclei after fluorescence in situ hybridization (FISH) with probes specific for chromosome 6 (red) and 7 (green). The small nucleus is diploid (two signals from each probe), whereas the large nucleus was determined to be octaploid. Nuclear DNA is counterstained with 4,6-diamino-2-phenylindole (DAPI) (blue).

to some extent, be related to the different culture systems used in these studies. It is also clear that in an embryo population in which mixoploidy is common, that is when the embryo comprises both normal diploid cells and abnormal polyploid cells (Viuff et al., 1999), cytogenetic investigations based on metaphase spreads may result in an unreliable estimate of the number of aberrant embryos because only a few cells in each embryo can be analysed accurately. This caveat is circumvented by the use of FISH with chromosome-specific probes allowing for analyses of interphase nuclei as well as mitotic configurations. Chromosome-specific probes recognizing sub-centromeric regions of chromosomes 6 and 7 in cattle have been used for determination of numerical chromosome aberrations on spreads of fixed interphase nuclei and sporadic mitotic configurations from bovine embryos. In an initial study, it was demonstrated that bovine blastocysts produced in vitro by oocyte maturation, fertilization and subsequent embryo co-culture with bovine oviduct epithelial cells for 7-8 days display a higher degree of mixoploidy ( $72 \%$ ) compared with that in blastocysts developed in vivo and collected from the uterus (25\%, Viuff et al., 1999; Figs 3 and 4). Moreover, among the mixoploid blastocysts produced in vitro, $83 \%$ contained $<10 \%$ polyploid cells, $13 \%$ contained between 11 and $25 \%$ polyploid cells and $4 \%$ contained $>25 \%$ polyploid cells compared with the mixoploid blastocysts developed in vivo that all contained $<10 \%$ polyploid cells. The significance of this high rate of mixoploidy among blastocysts produced in vitro is unknown. It is apparent that a proportion of these embryos is developmentally competent, as blastocysts produced by the same in vitro procedure have resulted in a pregnancy rate of $64 \%$ in this 


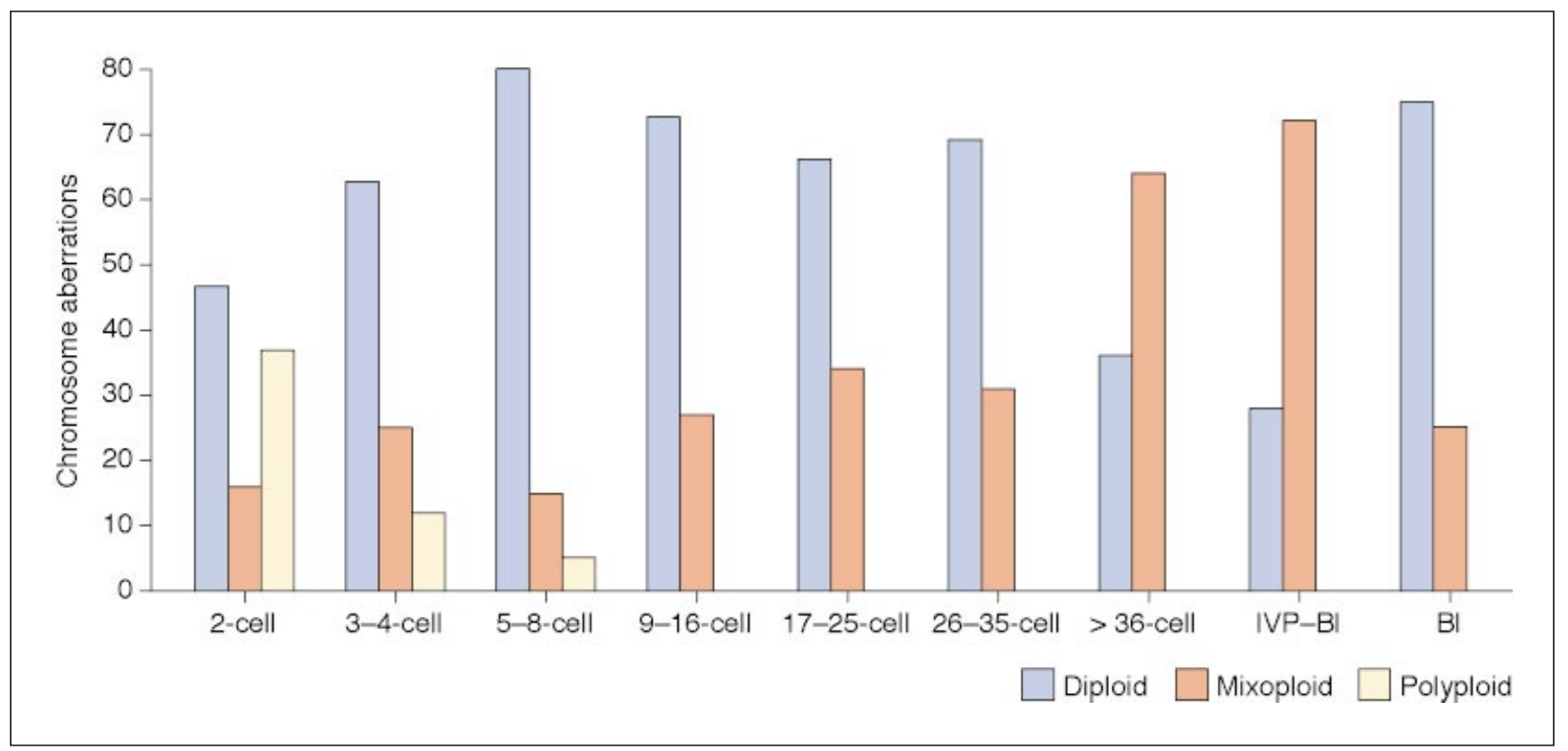

Fig. 4. Frequency of diploidy, polyploidy and mixoploidy in in vitro produced bovine embryos at different developmental stages, as indicated by the number of cells in the embryo, and in blastocysts developed in vivo. IVP-BI: in vitro produced blastocysts; BI: in vivo developed blastocysts.

laboratory (Schmidt et al., 1996). Furthermore, Hare et al. (1980) suggested that a proportion of $25 \%$ tetraploid trophoblast cells is compatible with pregnancy. It is possible that the polyploid cells are preferentially allocated to the extra-embryonic membranes, as has been shown in mice (James et al., 1995).

A chronological investigation from day 2 to day 5 after in vitro insemination was performed using the same chromosome-specific probes in combination with a technique for nuclear extraction from the embryos, to elucidate in more detail the stage at which these numerical chromosomal aberrations are established (Viuff et al., 2000). There was a gradual increase in the frequency of mixoploidy with increasing developmental stage of the embryo (Fig. 4). It was also found that initially after fertilization there was a considerable frequency of 'true' polyploidy, that is, when all cells of the embryo are polyploid. Moreover, at each specific day of collection, the slowest developing embryos showed the highest rates of polyploidy. The polyploid embryos were apparently eliminated before they cleaved beyond the eight-cell stage, that is, the stage at which major activation of the embryonic genome occurs in cattle (Camous et al., 1986). The basis of polyploidy is most likely established during gametogenesis or at fertilization in vitro. Other studies have shown that the frequencies of chromosomally abnormal germ cells vary according to the species examined, but in general chromosomally unbalanced gametes have been noticed more frequently among oocytes (2.4-14.6\%) than among spermatocytes (0-7\%; Lechniak et al., 1996). However, the basis of mixoploidy is most likely established either at fertilization in vitro or during culture of the embryos in vitro. Polyspermy and parthenogenetic activation can result in mixoploidy during the subsequent cleavage divisions (Handyside and Delhanty, 1997). This feature may be significant since $10-15 \%$ of the embryos are polyspermic and $3 \%$ are parthenogenetically activated within our in vitro production system (Avery et al., 1998). In addition, abnormalities imposed during in vitro culture of the embryo may cause abnormal chromosome segregation leading to mixoploidy from the first cleavage division. Thus, studies of human embryos produced in vitro that have been characterized as normal by routine examination for pronuclei have revealed an unexpectedly high proportion of post-zygotic chromosomal abnormalities (Munné et al., 1994, 1995; Harper and Delhanty, 1996; Delhanty et al., 1997).

\section{Perspectives}

Increasing cell biological understanding of the mechanisms regulating development of bovine preimplantation embryos leads to an increasing number of checkpoints at which to evaluate the normality of embryos created by technological procedures. Basic features, such as a proper activation of the embryonic genome and establishment and maintenance of the correct chromosome compartment in all blastomeres, are of great importance in this context. Although our cell biological analyses are still based on invasive procedures, there is a hope that they will give rise to non-invasive techniques or at least techniques that can be performed on biopsies of embryos. Further advances in the molecular 
understanding of cellular function is expected to lead to development of new arrays of intravital markers, which, together with the developments in bioimaging, for example multiphoton microscopy, may allow for evaluation of living embryos.

The project was supported by the Danish Agricultural and Veterinary Research Council and Bundesministerium für Wissenschaft und Verkehr der Republik Österreich.

\section{References}

Key references are identified by asterisks.

Assey RJ, Hyttel P, Greve T and Purwantara B (1994) Oocyte morphology in dominant and subordinate follicles Molecular Reproduction and Development 37 335-344

Avery B, Hay-Schmidt A, Hyttel P and Greve T (1998) Embryo development, oocyte morphology, and kinietics of meiotic maturation in bovine oocytes exposed to 6-dimethylaminopurine prior to in vitro maturation Molecular Reproduction and Development 50 334-344

Bilodeau-Goeseels S and Schultz GA (1997) Changes in ribosomal ribonucleic acid content within in vitro produced bovine embryos Biology of Reproduction 56 1323-1329

Camous S, Kopecny V and Flechon JE (1986) Autoradiographic detection of the earliest stage of $\left[{ }^{3} \mathrm{H}\right]$-uridine incorporation into the cow embryo Biology of the Cell 58 195-200

Chouinard LA (1971) A light and electron microscope study of the nucleolus during growth of the oocyte in the prepubertal mouse Journal of Cell Science $\mathbf{9}$ 637-663

Crozet N, Kanka J, Motlik J and Fulka J (1986) Nucleolar fine structure and RNA synthesis in bovine oocytes from antral follicles Gamete Research 14 65-73

Delhanty JDA, Harper JC, Ao A, Handyside AH and Winston RML (1997) Multicolour FISH detects frequent chromosomal mosaicism and chaotic division in normal preimplantation embryos from fertile patients Human Genetics 99 755-760

de Schmedt V, Crozet N and Gall L (1994) Morphological and functional changes accompanying the acquisition of meiotic competence in ovarian goat oocyte Journal of Experimental Zoology 269 128-139

De Sousa PA, Watson AJ, Schultz GA and Bilodeau-Goeseels S (1998) Oogenetic and zygotic gene expression directing early bovine embryogenesis: a review Molecular Reproduction and Development $\mathbf{5 1}$ 112-121

Di Berardino D, Hayes H, Fries R and Long S (1990) ISCNDA 1989. International system for cytogenetics nomenclature of domestic animals Cytogenetics and Cell Genetics 53 65-79

Fair T, Hyttel P and Greve T (1995) Bovine oocyte diameter in relation to maturational competence and transcriptional activity Molecular Reproduction and Development 42 437-442

Fair T, Hyttel P, Greve T and Boland M (1996) Nucleolus structure and transcriptional activity in relation to oocyte diameter in cattle Molecular Reproduction and Development 43 503-512

Fair T, Hulschof SCJ, Hyttel P, Boland M and Greve T (1997a) Nucleolus ultrastructure and transcriptional activity of bovine oocytes in preantral and early antral follicles Molecular Reproduction and Development 46 208-215

Fair T, Hulshof SCJ, Hyttel P, Boland M and Greve T (1997b) Bovine oocyte ultrastructure in primordial to tertiary follicles Anatomy and Embryology $195327-336$

Fair T, Driancourt MA, Byskov AG and Hyttel P (1998) Ultrastructure of oocytes in bovine foetal ovaries Serono Symposium Gametes: Development and Function p. 527 Eds A Lauria, F Gandolfi, G Enne and L Gianaroli

Fair T, Hyttel P, Lonergan P and Boland MP (2001) Immunolocalization of nucleolar proteins during bovine oocyte growth, meiotic maturation and fertilization Biology of Reproduction 64 1516-1525

Farin PW and Farin CE (1995) Transfer of bovine embryos produced in vivo or in vitro: survival and fetal development Biology of Reproduction 52 676-682

Frei RE, Schultz GA and Church RB (1989) Qualitative and quantitative changes in protein synthesis occur at the 8-16-cell stage of embryogenesis in the cow Journal of Reproduction and Fertility $\mathbf{8 6}$ 637-641

Fuhrer F, Mayr B, Schellander K, Kalat M and Schleger W (1989) Maturation competence and chromatin behaviour in growing and fully grown cattle oocytes Journal of Veterinary Medicine 36 285-291

Handyside AH and Delhanty JDA (1997) Preimplantation genetic diagnosis: strategies and surprises Trends in Genetics 13 270-275

Hare WCD, Singh EL, Betteridge KJ, Eaglesome MD, Randall GCB, Mitchell

D, Bilton RJ and Trounson AO (1980) Chromosomal analysis of 159 bovine embryos collected 12 to 18 days after estrus Canadian Journal of Genetics and Cytology 22 615-626

Harper JC and Delhanty JDA (1996) Detection of chromosomal abnormalities in human preimplantation embryos using FISH Assisted Reproduction and Genetics 13 137-139

Hay-Schmidt A, Viuff D, Greve T and Hyttel P Transcription in in vivo produced bovine zygotes and embryos Theriogenology (in press)

*Hendriksen PJM, Vos PLAM, Steenweg WNM, Bevers MM and Dieleman SJ (2000) Bovine follicular development and its effect on the in vitro competence of oocytes Theriogenology 53 11-20

Hozak P, Cook PR, Schofer C, Mosgoller W and Wachtler F (1994) Site of transcription of ribosomal RNA and intranucleolar structure in HeLa cells Journal of Cell Science 107 639-648

Hyttel P, Callesen H and Greve T (1986) Ultrastructural features of preovulatory oocyte maturation in superovulated cattle Journal of Reproduction and Fertility 76 645-656

Hyttel P, Viuff D, Avery B, Laurincik J and Greve T (1996) Transcription and cell cycle-dependent development of intranuclear bodies and granules in two-cell bovine embryos Journal of Reproduction and Fertility 108 263-270

*Hyttel P, Fair T, Callesen H and Greve T (1997) Oocyte growth, capacitation and final maturation in cattle Theriogenology 47 23-32

Iwasaki S and Nakahara T (1990) Incidence of embryos with chromosomal anomalies in the inner cell mass among bovine blastocysts fertilized in vitro. Theriogenology 34 683-690

Iwasaki S, Shioya Y, Masuda H, Hanada A and Nakahara T (1989) Incidence of chromosomal anomalies in early bovine embryos derived from in vitro fertilization Gamete Research 22 83-91

James RM, Klerkx AHEM, Keighren M, Flockhart JH and West JD (1995) Restricted distribution of tetraploid cells in mouse tetraploid-diploid chimaeras Developmental Biology $167213-226$

Kastrop PMM, Bevers MM, Destrée OHJ and Kruip TAM (1991) Protein synthesis and phosphorylation patterns of bovine oocytes maturing in vivo. Molecular Reproduction and Development 29 271-275

Kawarsky SJ, Basrur PK, Stubbings RB, Hansen PJ and King WA (1996) Chromosomal abnormalities in bovine embryos and their influence on development Biology of Reproduction 54 53-59

King WA, Niar A, Chartrain I, Betteridge KJ and Guay P (1988) Nucleolus organizer regions and nucleoli in preattachment bovine embryos Journal of Reproduction and Fertility 82 87-95

Kopecny V, Flechon JE, Camous S and Fulka J, Jr (1989) Nucleologenesis and the onset of transcription in the eight-cell bovine embryo: finestructural autoradiographic study Molecular Reproduction and Development 1 79-90

Kruip TAM and den Dass JHG (1997) In vitro produced and cloned embryos: effects on pregnancy, parturition and offspring Theriogenology 47 43-52

Kruip TAM, Cran DG, van Beneden TH and Dieleman SJ (1983) Structural changes in bovine oocytes during final maturation in vivo. Gamete Research 8 29-47

*Laurincik J, Thomsen PD, Hay-Schmidt A, Avery B, Greve T, Ochs RL and Hyttel P (2000) Nucleolar proteins and nuclear ultrastructure in preimplantation bovine embryos produced in vitro. Biology of Reproduction 62 1024-1032

Lechniak D, Switonski M and Sosnowski M (1996) The incidence of bovine diploid oocytes matured in vitro. Theriogenology 46 267-277 
Lonergan P, Monaghan P, Rizos D, Boland MP and Gordon I (1994) Effect of follicle size on bovine oocyte quality and developmental competence following oocyte maturation, fertilization and culture in vitro. Molecular Reproduction and Development 37 48-53

Memili E, Dominko T and First NL (1998) Onset of transcription in bovine oocytes and preimplantation embryos Molecular Reproduction and Development $\mathbf{5 1} 36-41$

Motlik J and Fulka J (1986) Factors affecting meiotic competence in pig oocytes Theriogenology 25 87-96

Motlik, J, Kopený V, Travnik P and Pivko J (1984) RNA synthesis in pig follicular oocytes. Autoradiographic and cytochemical study Biology of the Cell $\mathbf{5 0} 229-236$

Munné S, Weier HUG, Grifo J and Cohen J (1994) Chromosome mosaicism in human embryos Biology of Reproduction 51 373-379

Munné S, Alikani M, Tomkin G, Grifo J and Cohen J (1995) Embryo morphology, developmental rates, and maternal age are correlated with chromosome abnormalities Fertility and Sterility 64 382-391

Plante L, Plante C, Shepherd DL and King WA (1994) Cleavage and ${ }^{3} \mathrm{H}$ uridine incorporation in bovine embryos of high in vitro developmental potential Molecular Reproduction and Development 39 375-383

Schmidt M, Greve T, Avery B, Beckers JF, Sulon J and Hansen HB (1996) Pregnancies, calves and calf viability after transfer of in vitro produced bovine embryos Theriogenology 46 527-539

Schultz RM (1993) Regulation of zygotic gene activation in the mouse Bioessays 15 531-538

Sirard MA, Florman HM, Leibfried-Rutledge ML, Barnes FL, Sims ML and First NL (1989) Timing of nuclear progression and protein synthesis necessary for meiotic maturation of bovine oocytes Biology of Reproduction 40 1257-1263

Telford NA, Watson AJ and Schultz GA (1990) Transition form maternal to embryonic control in early mammalian development: a comparison of several species Molecular Reproduction and Development 26 90-100

Thibault C, Szollosi D and Gerard M (1987) Mammalian oocyte maturation Reproduction, Nutrition and Development 27 865-896

Thompson EM (1996) Chromatin structure and gene expression in the preimplantation mammalian embryo Reproduction, Nutrition and Development 36 619-635

Tomanek M, Kopecny V and Kanka J (1989) Genome reactivation in developing early pig embryos: an ultrastructural and autoradiographic analysis Anatomy and Embryology 180 309-316

Verheggen C, Le Panse S, Almouzni G and Hernandez-Verdun D (1998) Presence of pre-rRNA before the activation of polymerase I transcription in the building process of nucleoli during early development of Xenopus laevis. Journal of Cell Biology 142 1167-1180

Viuff D, Avery B, Greve T, King WA and Hyttel P (1996) Transcriptional activity in in vitro produced bovine two- and four-cell embryos Molecular Reproduction and Development 43 171-179

Viuff D, Hyttel P, Avery B, Vajta G, Greve T, Callesen H and Thomsen PD (1998) Ribosomal ribonucleic acid is transcribed at the 4-cell stage in in vitro produced bovine embryos Biology of Reproduction 59 626-631

*Viuff D, Rickords L, Offenberg H, Hyttel P, Avery B, Greve T, Olsaker I, Williams JL, Callesen H and Thomsen PD (1999) A high proportion of bovine blastocysts produced in vitro are mixoploid Biology of Reproduction $601273-1278$

*Viuff D, Greve T, Avery B, Hyttel P, Brockhoff PB and Thomsen PD $(2000$ Chromosome aberrations in in vitro produced bovine embryos at days 2-5 post insemination Biology of Reproduction 63 1143-1148

Wachtler F and Stahl A (1993) The nucelolus: a structural and functional interpretation Micron 24 473-505

Walker SK, Hartwich KM and Seamark RF (1996) The production of unusually large offspring following embryo manipulation: concepts and challenges Theriogenology 45 111-120

Watson AJ, Barcroft LC, Betts DH, De Sousa PA, Gilfoyle E, Looye J, PierreLouis J and Winger QA (1996) Maternal and embryonic control of bovine pre-attachment development: expression of oviductal and embryonic genes Archiv für Tierzucht 49 55-69

Watson AJ, Westhusin ME, De Sousa PA, Betts DH and Barcroft LC (1999) Gene expression regulating blastocyst formation Theriogenology $\mathbf{5 1}$ 117-133

Wilmut I, Young L, DeSousa P and King T (2000) New opportunities in animal breeding and production - an introductory remark Animal Reproduction Science 60-61 5-14

Yoshizawa M, Konno H, Zhu S, Kageyama S, Fukui E, Muramatsu S, Kim S and Araki Y (1999) Chromosomal diagnosis in each individual blastomere of 5 - to 10 -cell bovine embryos derived from in vitro fertilization Theriogenology 51 1239-1250 